\title{
Experiência formativa: crítica e paradoxo
}

Formative experience: criticism and paradox

Resumo - O artigo analisa a crítica social de Adorno, apontando os laços entre formação, sujeito e condições sociais e os efeitos para a educação (Bildung). A despeito da tradição neo-humanista e idealista e das certezas emancipatórias, a formação mostra sua face ilusória. É justamente em relação às questões educativas que o pensamento crítico de Adorno mais revela sua atualidade e potência para mostrar os paradoxos da própria educação. De tal crítica - apesar do paradoxo - decorrem determinadas exigências expressas numa dimensão ético-política e numa dimensão estética para a experiência formativa, cuja potência pode romper com o caráter meramente adaptativo da educação.

Palavras-chave: crítica social, Adorno, experiência formativa.

\begin{abstract}
The article analyzes Adorno 's social critique, pointing out the links between training, subject and social conditions and the effects for education (Bildung).In spite of the neo-humanist and idealist tradition and the emancipatory certainties, the formation shows its illusory face. It is precisely in relation to educational issues that Adorno's critical thinking reveals its actuality and power to show the paradoxes of education. From such criticism - in spite of the paradox - certain requirements expressed in an ethical-political dimension and in an aesthetic dimension for the formative experience, whose potency can break with the merely adaptive character of education.
\end{abstract}

Key words: social criticism, Adorno, formative experience.

A inteligência é uma categoria moral.

Adorno, Minima moralia

As profundas articulações entre sujeito e crítica social desenvolvidas no "interior da experiência filosófica” (SAFATLE, 2009, p. 170) de Adorno, o levam a pensar a educação pelo avesso, ou seja, a partir da negatividade. Essas reflexões aparecem especialmente nos textos Semi-formação (1959), 
Educação contra a barbárie (1965), Educação após Auschwitz (1965), Educação e emancipação (1969). O caráter crítico ali contido provoca um "fascínio irritante" para teoria da educação, justamente porque, ao basearse na dialética negativa com sua proposta de uma autocrítica da própria filosofia, Adorno vincula-se à tradição teórica neo-humanista da Bildung ao mesmo tempo em que denuncia seu caráter ilusório (SCHÄFER, 2003).

O olhar filosófico de Adorno mostra, então, os laços entre formação, sujeito e condições sociais que forjaram a moderna "autocompreensão pedagógica” como "uma herança do esclarecimento" (SHÄFER, 2003, p. 9). Uma crítica dessa natureza produz efeitos na educação, na medida em que força a revisão das ilusões e das certezas emancipatórias. E talvez seja relativamente às questões educativas que o pensamento crítico de Adorno mais revele sua atualidade e potência para mostrar os paradoxos da própria educação. Minha intenção com este texto é mostrar, como sugere o tema do Congresso ${ }^{2}$, a atualidade da crítica de Adorno, indicando que de tal crítica - apesar do paradoxo - decorrem determinadas exigências que se traduzem numa dimensão ético-política e numa dimensão estética para a experiência formativa, cuja potência pode romper com o caráter meramente adaptativo da educação.

II

Comecemos com uma breve referência à historicidade conceitual. O conceito de formação/educação ${ }^{3}$, objeto da crítica adorniana, está fortemente enraizado na tradição ocidental, é originário do mundo grego que o denomina Paidéia. No final do século XVIII, com o neo-humanismo, o idealismo e o romantismo surge um retorno a esse ideal, que na língua alemã se conhece com o nome de Bildung, "um refinamento do intelecto, da sensibilidade e do julgamento" (REICHENBACH, 2002, p. 409), que nós costumamos traduzir por formação e também educação no sentido amplo. Em grande parte, as discussões teóricas sobre Bildung encontram-se em Herder, Humboldt, Schiller, Hölderlin, Novalis, Goethe, Kant, Hegel e são conhecidas como a "determinação do homem" ( MASSCHELEIN, 2003, p. 140). Vinculam-se a uma visão antropomórfica, que aposta na condição da 
razão para promover o humano. Não me deterei em momentos expressivos da formação como a própria Paidéia e a humanitas latina, por não ser de interesse para esse momento proceder uma reconstrução histórico-sistemática. Enfatizarei o significado da Bildung, pela sua profunda relação com a metafísica da subjetividade, decisiva para a ideia da educação como emancipação, base de referência para a crítica de Adorno.

A Bildung tematiza a subjetividade a partir de dois princípios: o princípio da autonomia ou autodeterminação e o princípio da unidade das diferenças. A partir desse pressuposto, a educação é a capacidade de autodeterminação racional, uma liberdade do sujeito na criação de si. A subjetividade aparece sob duplo aspecto: como uma capacidade pressuposta para a autonomia ${ }^{4}$ e como realização dessa autonomia pela educação. Esse princípio da autonomia não vale apenas para o indivíduo singular, mas para a humanidade como um todo, pois a história tende à perfectibilidade do homem como ser social. Daí que a educação não se define apenas subjetivamente, mas mediada na relação com o mundo e a reconciliação (ou a harmonia) é o telos das experiências contraditórias, a unidade conciliadora das diferenças, como propôs o idealismo hegeliano. O indivíduo, enquanto ser racional, é capaz de elevar-se ao universal e interiorizar a ideia de humanidade. Por isso, Gadamer (1990, p. 18) dirá que Hegel desenvolveu com agudeza o conceito de formação (Bildung), associando a ideia de ser espiritual e racional, capaz de romper com o imediato e o natural para chegar ao mais alto nível de abstração, capaz de integrá-lo na totalidade. Vale lembrar que essa superação do imediato sempre teve força em nossa herança cultural para distinguir o homem educado como aquele que alcança a universalidade capaz de unir nosso eu a toda humanidade.

A formação é a criação de si, vinculada ao mundo no qual o sujeito está inserido, ou seja, um sujeito que age de acordo com a moral universal, de forma autônoma, criativa e independente. Para Humboldt, um dos importantes formuladores da teoria clássica da educação, o homem forma

\footnotetext{
${ }^{4}$ A autonomia é um conceito moral baseado na vontade de sujeitos racionais, conforme Kant o apresenta da Fundamentação da metafísica dos costumes (1785): "Autonomia da vontade é a qualidade da vontade, pela qual ela é uma lei para si mesma (independentemente de toda a qualidade dos objetos do querer)" (1974, p. 74). Esse conceito se constitui num importante ideal que orienta o projeto iluminista e o idealismo alemão, na perspectiva de libertar o homem de todas as determinações externas e é assumido como uma orientação fundamental do projeto educativo moderno. É um conceito ligado à ideia de maioridade, também defendida por Kant.
} 
a personalidade livre e singular numa multiplicidade de experiências autodeterminadas, numa ação recíproca entre o homem e a cultura. Formação é um trabalho de si mesmo, numa abertura dialética entre a experiência no mundo e um projeto de mundo. Assim se expressa Humboldt: "O verdadeiro fim do homem (...) é a formação máxima e o mais proporcional possível de suas forças, para integrá-las num todo. Para isso a liberdade é a condição primeira e indispensável." Mas esta liberdade deve estar associada a uma "multiplicidade de situações", pois mesmo "o mais livre e independente dos homens, deslocado para circunstâncias uniformes, forma-se de modo mais restritivo" (196o, p. 64).

O homem, então, é formado no confronto de suas experiências, não sendo determinado nem pela natureza nem pelo fundamento teológico, mas pela suas próprias ações e escolhas, por meio do pleno desenvolvimento de suas forças - uma experiência de si. Para Humboldt, todo o pensar do homem "é apenas uma tentativa do espírito de tornar-se compreensível a si mesmo e seu agir uma tentativa de querer se tornar livre e independente" (196o, p. 235). O homem educado busca a si mesmo, participando do ideal de humanidade, o que projeta um programa de transformação social (uma teleologia ou finalidade), através da formação da identidade do eu e da formação do caráter.

Esse sujeito livre, independente e integrado numa totalidade social como é expresso na Bildung revela-se um conceito ambicioso demais, pois o indivíduo, ao contrário de uma soberania plena, encontra-se determinado numa rede de relações e de dependência, tanto de ordem econômica, como social, moral e psíquica, como é apontado pelas críticas da razão no século XX. Caberá a Adorno a mais dura crítica, em que o ponto de partida se encontra no Esclarecimento e na negação de suas aspirações. Com o fascismo e a fábrica de morte (campos concentração) a crítica adorniana indica que a barbárie não é uma "recaída atrás do Esclarecimento, mas sua conseqüência. A fantasia iluminista, que uma compreensão de si próprio e do mundo resulta de uma autodeterminação racional, é vista como ingênua” (SCHÄFER, 2003, p. 12). As análises sociológicas e epistemológicas indicam que não há um sujeito autônomo fundado em si mesmo; antes disso, ele é levado à submissão social hegemônica (o mundo administrado), à uma vida padronizada, que solapa a ideia de autodeterminação. Há uma perda de confiança na possibilidade do sujeito apropriar-se conceitualmente do mundo. Ao contrário, estará 
determinado pelo mundo, o que o leva a perder parte de sua soberania. $\mathrm{O}$ mundo e o si mesmo que resultam do pensamento objetificador constituem um mundo reduzido que exige a submissão do sujeito às regras do conhecimento. Assim, a autoafirmação do sujeito é uma perda de si mesmo. Perda de tudo aquilo que escapa ao pensamento conceitual.

Tanto o fascismo como também o comunismo estalinista e o americam way of life passam a ser interpretados pela crítica adorniana como variantes de um mesmo processo, que incluem a dialética entre progresso e retrocesso, entre civilização e barbárie. Nosso tempo confrontou-se com um fundo terrível que a razão iluminista tentou eliminar, por meio de estratégias de controle e domínio. A tentativa de compreender esse tempo na Dialética do Esclarecimento, resulta num diagnóstico sombrio, em que a autodestruição estaria na base da barbárie. Essa dinâmica, na medida em que abrange toda a cultura, revela também o lado repressor da educação que embasa a constituição do sujeito pelo domínio da natureza interna. As capacidades do eu se formam pela repressão pulsional, impossibilitando a experiência de si mesmo. A formação do sujeito proposta pela Teoria da Bildung revela-se, à luz da crítica adorniana, como um processo repressivo da formação da identidade e o próprio projeto civilizatório depende da repressão da dinâmica das pulsões. O canto XII da Odisséia, de Homero é interpretado na Dialética do esclarecimento como emblemático da repressão pulsional. Ao voltar para casa, Ulisses é aconselhado, a fim de não haver risco de sedução pelo doce canto das sereias que habitavam uma das ilhas do percurso de retorno, a colocar cera nos ouvidos dos navegadores, de modo a impedir a audição. Ele, curioso para ouvir, pede para ser amarrado ao mastro e, dessa forma, embora ouça o canto das sereias, resiste ao desejo, chegando intacto ao destino final. A repressão de tudo o que é corpóreo, de tudo o que é relativo à natureza garante a identidade do eu. Há portanto, uma progressiva submissão da subjetividade.

A civilização caminhou rumo a uma crescente racionalização, onde as ações humanas se revestem em violência e manipulação. Disso resulta a repressão da natureza interna e o homem se torna vítima subjugada pelas forças incontroláveis. Uma repressão dessa ordem conduz ao fechamento do sujeito em sua própria interioridade, impedindo que o eu se abra à alteridade e se reconheça na cultura. Em Minima moralia, Adorno escreve um aforismo notável sobre a as conseqüências da falsa identidade: 
“Em muitas pessoas já é um descaramento dizer 'Eu'” (1998, v. 4, p. 55). Revela-se aí uma radical expropriação da experiência formativa.

O próprio conhecimento e esclarecimento convertem a reflexão em produtos de massa, em que há muitas fórmulas e nenhuma autoconscientização. Daí que "o medo diante do abismo do Eu é dissipado pela consciência de que nada disso afinal é tão diverso assim de uma artrite (...). Com isso os conflitos perdem o aspecto ameaçador. Eles são aceitos mas de forma alguma curados, e sim meramente encaixados na superfície da vida padronizada" (ibidem, p. 73).

A formação na vida acadêmica também não escapa a esse diagnóstico. No texto “A filosofia e os professores", palestra proferida na casa do estudante de Frankfurt e publicada em 1962, Adorno expõe os problemas decorrentes da falta de formação cultural sólida entre candidatos ao cargo de professor na Universidade, revelando preocupação com o prejuízo para os futuros alunos que "estão ameaçados de danos maiores por parte do espírito deformado e inculto" (1998, v. 10-2, p. 475) dos professores. Para posicionar sua crítica, reivindica o papel que a filosofia deveria ocupar na Universidade que não é uma mera dimensão profissional mas a "formação viva atual" (1998, v. 10-2 , p. 476).

III

Todas essas críticas têm em comum o fato de produzirem um abalo nas crenças mais enraizadas da cultura ocidental, especialmente aquelas que constituem a base da ação educativa, desde a modernidade: as certezas emancipatórias, a identidade do eu, a autonomia e a maioridade como decorrência do ser racional e a libertação do homem pela moral e pelo conhecimento, herdados da racionalidade iluminista. Essas observações se referem aos efeitos teóricos da crítica que apontam os limites de nosso próprio agir. Ou seja, essa crítica oferece uma visão desiludida da autodeterminação pressuposta no conceito de formação (Bildung). Associada à atualidade dessa crítica, há uma crítica proveniente do campo prático da educação brasileira, expressa numa torrente de queixas e lamentações de professores, tanto em relação às políticas públicas, como em relação às instituições e aos alunos que teriam perdido o amor pelo conhecimento, pelo trabalho intelectual, o respeito pelos clássicos. Longe de buscar a mediação por processos simbólicos, de compreender a ideia de 
humanidade no mais alto nível, estamos circunscritos ao imediatismo, ao consumismo e ao interesse do agir orientado somente pelos nossos desejos. Encontramo-nos disponíveis para diferentes tipos de sedução, especialmente aqueles que estimulam uma vida sem esforço e também expostos aos ataques de poderes econômicos e do consumismo que favorecem o egoísmo, a frivolidade e a indiferença e geram um sujeito alienado em relação ao outro e uma sociedade de controle. Percebe-se uma alteração no contexto histórico que fragilizou o vínculo do homem com um projeto de mundo, como já percebia Adorno desde os fins da década de quarenta do século XX. Nessa perspectiva, o caráter crítico de seu pensamento o leva a aguçar ao máximo a tensão entre a crença na educação e o caráter regressivo da razão. Ele dirá que "a educação tem sentido unicamente como educação dirigida a uma auto-reflexão crítica" (1998, v. 10-2, p. 676). Contra a servidão que torna indigna as pessoas, restaria "empreender algo mediante a educação e o esclarecimento" (1998, v. 10-2, p. 69o). Isso não deixa de ser uma afirmação surpreendente, uma vez que Adorno sempre desconfiou das certezas emancipatórias. De qualquer modo, o filósofo reconhece que a educação seria nossa possibilidade para que não recaíssemos na barbárie, desde que desencantássemos seu conceito de um pensamento objetificador que conduz à uniformização, gerando a fraqueza do ego, raiz das formas latentes de fascismo. Ou seja, a irritação e a fascinação que Adorno provoca configura-se justamente nessa tensão entre manter a promessa da teoria educacional neo-humanista e analisar, ao mesmo tempo, seu fracasso (SCHÄFER, 2003). Isso vem acompanhado "da esperança de uma experiência educativa que se abre ao mistério do eu e do mundo" (SCHÄFER , 2003, contracapa). Diante disso, Schäfer considera que a primeira exigência da educação é que "Auschwitz não se repita", conforme o "novo imperativo categórico" (1998, v. 6, p. 358) proposto por Adorno $^{6}$. É imperativo porque nesse recordar está em questão o próprio destino da humanidade. Não é uma escolha, mas um imperativo que provém da violência histórica e que exige uma luta contra o esquecimento

\footnotetext{
${ }^{5} \mathrm{O}$ "novo imperativo categórico", afirma: "Hitler impôs um novo imperativo categórico aos homens em estado de não-liberdade: a saber, direcionar seu pensamento e seu agir de tal forma que Auschwitz não se repita, que nada de semelhante aconteça" (Adorno, 1998, v. 6, p.358).

${ }^{6}$ Ver tese de SAVI, Pedro. Educação e memória do sofrimento em Adorno. 2017 Tese (Doutorado em Educação)Pontifícia Universidade Católica do Rio Grande do Sul, Porto Alegre, 2017.
} 
e o recalque, para não haver repetição. Aqui se percebe a contribuição freudiana sobre a relação entre memória e esquecimento, expressa pelas "resistências" do recalcamento, que obstaculizam as lembranças traumáticas e conduzem a "compulsão da repetição" (FREUD, 1969, p. 166). O que deve ser lembrado tem relação com a história da violência, por isso os acontecimentos que aniquilam a humanidade não podem ser esquecidos, como é o caso da destruição quase completa da população da América no séc. XVI (considerada também um genocídio), a escravidão em massa da população africana e os genocídios do século XX com os judeus, armênios e ainda em Camboja, em Timor, na antiga Iugoslávia, na Ruanda. Aqui cabe também perguntar pelas violências em nosso país e a facilidade com que as esquecemos.

Gagnebin observa que o imperativo proposto por Adorno "não diz que devemos nos lembrar sempre de Auschwitz; mas sim que devemos fazer tudo para que algo semelhante não aconteça” (2006, p. 100). Não se trata de apenas lembrar, priorizando a memória do passado em detrimento do presente, mas o trabalho de esclarecimento, de rememoração, ou seja, o modo pelo qual "o passado é tornado presente" (Adorno, 1998, v. 10-2, p. 569), um trabalho pedagógico capaz de oferecer resistência à opressão e à violência. Essa exigência é o que considero como uma dimensão ético-política da educação, decorrente da atualidade da crítica adorniana. Sem esse trabalho de rememoração, podemos ficar insensíveis às violências que nos cercam, sem escapar à repetição. Ao olharmos os genocídios ocorridos no século XX, percebe-se que o novo imperativo categórico não foi cumprido. Parece que temos uma tendência ao esquecimento, por isso Adorno insiste na luta contra o esquecimento.

Last but not least gostaria de indicar a relevância da estética para a experiência formativa, como mais um elemento que corrobora a atualidade da crítica adorniana, constituindo a dimensão estética da educação. A Teoria estética, obra inconformista, mostra especialmente o limite do pensamento conceitual na impossibilidade de apreender toda a verdade, o que se torna produtivo para pensar a educação para além de qualquer parâmetro utilitarista, de estruturas autoritárias e dogmáticas ou de ajuste às necessidades do mercado. Há muito mais a compreender pela arte, ela tem um momento não repressivo capaz de revelar o estranho, de trabalhar contra as condições petrificadas das relações sociais e de dizer o que nós não conseguimos dizer. Ou seja, a estética opera naquele âmbito 
da estranheza que o pensamento conceitual não atinge, pois a reflexão tende a tudo objetificar, nivelando singularidades, absorvendo qualquer alteridade. Por isso Adorno considera a obra de arte uma antítese à realidade, uma espécie de antídoto contra a alienação, que invoca o estranhamento, contra toda a harmonia forçada pela indústria cultural. A estética, diz Adorno, "deve defender o não-idêntico que a compulsão à identidade oprime na realidade" (ADORNO, 1998, v. 7, p. 14). Ao acentuar a relevância da estética, Adorno mostra também o equívoco de uma formação que se detém apenas no conhecimento, que está presa aos desígnios da objetificação, indicando que nosso acesso ao mundo das escolhas éticas e à própria criação do sujeito dependeria da sensibilidade e da intuição. O que põe em movimento esse outro lado da razão - o sentimento, a sensibilidade, as emoções e o corpóreo - é a experiência estética.

A arte autêntica não alivia a dor nem o sofrimento, tampouco aquieta ou tranqüiliza. Seria muito menos ainda redutível a um mero entretenimento. Ela provoca uma comoção, porque deixa transparecer algo outro que não ela mesma, que expõe o irreal da realidade. $\mathrm{O}$ sofrimento humano encontra na arte uma forma de expressão, mas não tem intenção de evitar a dor, antes, ela dá forças, provoca o calafrio estético. A dor é tocada pelo que Adorno chama de belo natural, ou seja,

o vestígio do não idêntico nas coisas. (...) A dor perante o belo, em nenhum lado mais viva do que na experiência da natureza, é tanto nostalgia do que ele promete, sem que esse belo aí se revele, como o sofrimento perante a insuficiência da aparição que o recusa, ao desejar a ele assemelhar-se (1998, v. 7, p. 114).

A autêntica obra de arte se subtrai às intenções humanas e seu objeto é indeterminado. Ela é aparição de uma realidade que se torna permanentemente inconcebível: "As obras de arte tornam-se aparições no sentido mais rico do termo, aparições de um outro, quando o acento incide sobre o caráter irreal da sua realidade" (ibidem, p. 123).

Esse modo de aparição difere de qualquer fenômeno da realidade que é apreendido pelo conhecimento, pois "em toda a obra de arte genuína aparece algo que não existe” (ibidem, p. 10o). Ela se movimenta numa ambiguidade entre um intenso estranhamento e a promessa de contato vivo com a realidade. $\mathrm{O}$ que aparece, o outro, a alteridade ou, ainda, a 
diferença é o ponto de entrecruzamento com a ética e com a experiência de subjetivação, decisivo para uma educação não instrumentalizadora. É uma liberdade que aparece pela indeterminação (SEEL, 200o, p. 37), em que a arte nos indica que o mundo não é plenamente compreendido no âmbito conceitual e que pode deixar um espaço para uma promessa de vida. Abrir o espaço para a alteridade está associado à possibilidade formativa da estética, como o momento em que nossa vida não se deixa dominar pelo espírito de apropriação, que a realidade se enriquece pela aparição, desdobra diferenças.

Na Teoria estética, Adorno mostra que o pensamento conceitual tem limites e o caráter sempre dinâmico e imprevisível da criação artística e da experiência estética ultrapassa as questões de banalização cultural, tornando-se um refúgio para sustentar a subjetividade contra as forças objetivas massificadoras e contra uma educação niveladora. A arte sempre tem um momento utópico, uma vez que sua presença traz a possibilidade do não-existente, transcende os antagonismos da vida cotidiana, emancipa a racionalidade do confinamento empírico imediato. Nessa perspectiva, a estética pode ampliar a experiência formativa, tornando-nos mais atentos à trama de elementos que envolvem a própria constituição do sujeito. Uma sensibilidade refinada pela experiência estética promove a imaginação, rompe com certos enclausuramentos, criando novas condições para adensar a experiência formativa.

Adorno desafia a compreensão moderna da educação e indica sua negatividade, em termos de uma diferença que não é percebida dentro do pensamento identificador. Força a pensar uma experiência formativa que supere os limites do comportamento convencional e caricato, que rompa com o "eu fraco". Embora a educação não cumpra a promessa de autonomia e de autodeterminação não é possível abandoná-la - é irrenunciável. Se, por um lado, é em relação à educação que o pensamento crítico de Adorno mais revela sua atualidade, insistindo no sentido emancipatório; por outro lado, o filósofo reconhece as dificuldades de realizá-la devido à imposição da organização social e das condições simbólicas que favorecem a heteronomia, pois todas as formas de vida social já estão desfiguradas pelo pensamento totalizador. 
Promover a autonomia e a emancipação através de uma socialização cingida no pensamento identificador é o paradoxo apontado por Adorno, de acordo com a interpretação de Schäfer (2005, p. 205-6). Uma conclusão dessa ordem solapa uma solução fácil para a formação, uma vez que não se pode simplesmente saltar fora do pensamento identificador. A exigência diante desse paradoxo consiste em reconhecer que os problemas devem ser interpretados em diferentes perspectivas, num pensar constelador ${ }^{7}$, como chamou Adorno, para que escapem à certeza aparente da identificação e não deslizem para a estereotipia. Segundo o filósofo, na constelação encontram-se campos de força, conteúdos em movimento, tensões entre as diversas camadas de sentido, que postas em perspectiva ajudam a explicitá-las. Assim, o pensar constelador permite ver as diferentes interpretações a respeito de algo sob nova luz. Nesse jogo entre diferenças, que escapa a lógica da identidade, a dimensão ético-política e a dimensão estética mostram a face de uma formação mais adequada à emancipação, sem recair em certezas salvacionistas.

\section{Referências}

ADORNO, Theodor. Negative Dialetik. In: ADORNO, Theodor. Gesammelte Schriften. Herausgegeben von Rolf Tiedemann. Darmstad: Wissenschaftliche Buchgesellschaft, 1998. v.6.

ADORNO, Theodor. Ästhetische Teorie. In: ADORNO, Theodor. Gesammelte Schriften. Herausgegeben von Rolf Tiedemann. Darmstadt: Wissenschaftliche Buchgesellschaft, 1998, v. 7 .

ADORNO, Theodor. Kulturkritik und Gesellschaft II. Herausgegeben von Rolf Tiedemann. Darmstad: Wissenschaftliche Buchgesellschaft, 1998. v.10-2.

ADORNO, Theodor. Minima Moralia. Herausgegeben von Rolf Tiedemann. Darmstad: Wissenschaftliche Buchgesellschaft, 1998. v.4.

FREUD, Sigmund. Recordar, repetir, elaborar. In: Obras psicológicas completas de Sigmund Freud; edição standard. v. XII. Rio de Janeiro: Imago, 1969. p. 163-171.

\footnotetext{
${ }^{7}$ O termo constelação acha-se disperso na obra de Adorno, mas na Dialética negativa o filósofo aborda uma outreidade e uma diferença que não se deixam apreender, para as quais ele sugere a metáfora da constelação, que permite escapar à certeza aparente da identificação e ver o outro sob nova luz.
} 
GADAMER, Hans-Georg. Hermenutik I Warheit und Methode. In: GADAMER, Hans-Georg. Gesammelte Werke. Tübingen: Mohr Siebeck, 1990, v. 1.

GAGNEBIN, Jeanne Marie. Lembrar escrever esquecer. São Paulo: Editora 34, 2006. Avaliacão cega x 2.

MASSCHELEIN, Jan; RICKEN, Norbert. Do we (still) need the concept of Bildung? Educational Philosophy and Theory. Oxford/UK, Malden/USA, v. 35, n. 2, p. 139$154,2003$.

REICHENBACH, Roland.On irritation and transformation: a-teleological Bildung and its significance for the democratic form of living. Journal of Philosophy of Education. Oxford/UK; Malden/USA, v.36, n.3, p. 409-419, 2002.

SAFATLE, Vladimir. A unidade de uma experiência filosófica plural. In: ALMEIDA, Jorge de ; BADER, Wolfgang (Orgs.). Pensamento alemão no século XX. São Paulo: Institut Goethe, Cosacnaify, 2009, p. 159-179

SCHÄFER, Alfred. Theodor W. Adorno: Ein pädagogisches Porträt. Weinheim: Beltz, 2003.

SCHÄFER, Alfred. Einführung in die Erziehungsphilosophie. Weinheim und Basel: Beltz, 2005 .

SEEL, Martin. Ästhetik des Erscheinens. München: Carl Hans Verlag, 2000.

\section{Endereço Postal:}

Programa de Pós-Graduação em Educação da PUCRS

Av. Ipiranga 6681, Porto Alegre - RS, Brasil

Data de recebimento: 25/05/2018

Data de aceite: 17/09/2018 